\title{
The role of neurochemical factors in the chronic mercury intoxication development
}

\author{
Irina Kudaeva ${ }^{1, *}$, Olga Naumova $^{1}$, Olga Dyakovich ${ }^{1}$, and Liudmila Masnavieva ${ }^{1}$ \\ ${ }^{1}$ East-Siberian Institute of Medical and Ecological Research, 12a microdistrict, 3, Angarsk, 665827, \\ Russia
}

\begin{abstract}
The search of pathogenetic targets for the diagnosis and treatment of mercury intoxication is an actual problem. The aim of the investigation was to study the dynamics of changes in neurochemical parameters in workers in contact with mercury and in persons in the early and distant period of intoxication. A prospective cohort examination included 69 men, exposed to mercury vapors in the workplace (1) and 36 patients in the distant (2) and 18 - in initial period of chronic mercury intoxication (3). Serotonin, histamine, catecholamines and their metabolites were determined in blood plasma. The maximum number of indicators that changed in the dynamics of the survey was registered in the group 2. Dopamine level increased by a maximum value - $284 \%$, noradrenaline $-124 \%$. Only the noradrenaline content changed in 3.2 times in patients in the group 3 and in 1.4 times in experienced workers without pathology. This changes in experienced workers was partially offset by its transition to inactive metabolite normetanephrine. The increase of noradrenaline concentration was not accompanied by increase of its metabolite level in the group 3. But the increase of the dopamine, serotonin and histamine joined in the distant period of chronic mercury intoxication.
\end{abstract}

\section{Introduction}

Issues related to the diagnosis of disorders arising from exposure to neurotoxic substances, that have pathogenetic significance for the formation of concomitant pathology, are relevant at present time. The study of the mechanisms of signal transduction activity disorders in the process of the formation of psychopathological and neurological disorders can determine various neurotransmitter systems when exposed to neurotoxicants is promising [1-2].

Mercury is such a substance and belongs to environmental pollutants. Its impact poses a serious threat to public health. Entering the human body with food, water and during breathing, mercury goes through a difficult path of migration and transformation. Mercury vapors in the brain, due to the constant oxygen flow are oxidized and accumulate in it, because the release of mercury ions through the blood-brain barrier of the brain is significantly difficult compared to atomic mercury [3-4].

\footnotetext{
Corresponding author: kudaeva_irina@mail.ru
} 
Mercury intoxication of adults leads to serious psychological and neurological deficits, which may contribute to the vulnerability of dopamine neurons and a tendency to develop Parkinson's disease [5].

It is also known that mercury has the ability to accumulate in neurons of the blue nucleus [6]. The resulting dysfunction of noradrenaline (NA) affects a wide range of neurons of central nervous system (CNS) and can cause a number of neurodegenerative (Alzheimer's, Parkinson's and motor neurons), demyelinating (multiple sclerosis) and psychiatric conditions (severe depression and bipolar disorder). It was also established that neurochemical changes in individuals, exposed to mercury, are characterized by the increase of the NA concentration in the distant period of intoxication, and increased levels of dopamine (DA), serotonin (SER) and histamine (HIST) [7].

Besides the scientists have identified a relationship associated with clinical symptoms and characterizing the signs of the pathological process between indicators of emotional and cognitive spheres, bioelectric brain activity and neurotransmitter metabolism [8].

Thus, the search for pathogenetic targets for the diagnosis and treatment of mercury intoxication is an urgent problem. The aim of this investigation was to study the dynamics of changes in neurochemical parameters in workers in contact with mercury and in individuals in the early and distant period of intoxication.

\section{Materials and methods}

A prospective cohort examination with a range of 4-5 years included 69 men, exposed to mercury vapors in the workplace (average age $45.4 \pm 1.1$ years, average experience $17.1 \pm$ 1.1 years), patients in the distant and initial period of chronic mercury intoxication (CMI) in the amount of 36 (average age $50.7 \pm 1.1$ years, average experience $14.7 \pm 1.1$ years) and 18 (average age $46.0 \pm 1.4$ years, average experience $15.7 \pm 1.7$ years) people, respectively.

The inclusion criteria were: written consent of the person to participate in the study, work experience under exposure to mercury vapor for 5 years or more, or the presence of a diagnosis of chronic mercury intoxication. The exclusion criteria included a history of complications in the form of myocardial infarction, stroke, oncopathology, the absence of accompanying diseases that contribute to the development of encephalopathy (arterial hypertension 2-3 degrees, diabetes mellitus, cerebral atherosclerosis, etc.), the absence of hemodynamically significant changes according to Doppler ultrasound, duplex examination of cerebral vessels, leukoaraiosis foci according to the results of the nuclear magnetic resonance imaging of the brain, age over 60 years.

The main professional groups of workers were represented by machine operators, equipment repair mechanics, locksmiths of control and measuring devices, electricians, and engineering and technical workers. The nature of the labor activity of these professions was characterized by the following points: monitoring the technological process directly in the workshop, control from the panel rooms; carrying out repair and adjustment work in the shop and in work and repair shops; making current and operational decisions on the regulations of the technological process and the efficient operation of equipment, carried out both in office premises and directly in the workshops.

Neurochemical parameters: serotonin, histamine, catecholamines (DA, NA, adrenalin) and their metabolites (normetanephrine $(\mathrm{NMN})$, metanephrine) were determined in blood plasma, obtained using EDTA, a solid-phase competitive enzyme-linked immunosorbent assay using appropriate test kits ("LDN"). The results were read using a BioTek reader (USA).

The statistical analysis system STATISTICA 6.0 Stat_Soft ${ }^{\circledR}$ Inc. used for statistical processing of results. The normal distribution of quantitative indicators was checked using the Shapiro-Wilks test. The Wilcoxon Matched Pairs Test was used to compare quantitative 
traits in two related samples. Differences were considered statistically significant at $\mathrm{p}$ $<0.05$. The results are presented as the median and interquartile range (25th and 75th percentiles).

This work didn't infringe on the rights and didn't endanger the examined, was carried out with the informed consent of the patients, in accordance with the ethical standards of the Helsinki Declaration (2000).

\section{Results}

The results of the study indicate indicate that there are violations in the dopamine content exceeding the upper range of reference values (up to $100 \mathrm{pg} / \mathrm{ml}$ ) during the first and repeated examination in persons exposed to mercury and without signs of intoxication (Table 1).

Table 1. Dynamics of changes of the blood neurochemical parameters in groups of subjects exposed to mercury, Med (Q25-Q75)\

\begin{tabular}{|c|c|c|c|c|c|c|}
\hline \multirow[t]{2}{*}{ Index, unit } & \multicolumn{2}{|c|}{$\begin{array}{c}\text { Internship workers } \\
n=69\end{array}$} & \multicolumn{2}{|c|}{$\begin{array}{r}\text { Patients with CMI } \\
\text { (initial period), } n=18\end{array}$} & \multicolumn{2}{|c|}{$\begin{array}{c}\text { Patients with CMI } \\
\text { (distant period), } n=36\end{array}$} \\
\hline & 1 & 2 & 1 & 2 & 1 & 2 \\
\hline HIST, ng/ml & $\begin{array}{c}0.99 \\
(0.81-1.22)\end{array}$ & $\begin{array}{c}1.1 \\
(0.84- \\
1.46)\end{array}$ & $\begin{array}{c}1.02 \\
(0.44- \\
1.7)\end{array}$ & $\begin{array}{c}1,62 \\
(0,79- \\
2,43)\end{array}$ & $\begin{array}{c}0,66 \\
(0,26- \\
1,37)\end{array}$ & $\begin{array}{c}1,08 \\
(0,7- \\
2,2)\end{array}$ \\
\hline p Wilcoxon Test & \multicolumn{2}{|c|}{0.3} & \multicolumn{2}{|c|}{0.3} & \multicolumn{2}{|c|}{0.04} \\
\hline $\mathrm{SER}, \mathrm{ng} / \mathrm{ml}$ & $\begin{array}{c}94.2 \\
(58.1-141)\end{array}$ & $\begin{array}{c}61.8 \\
(15.9- \\
116)\end{array}$ & $\begin{array}{c}88.6 \\
(74.7- \\
136)\end{array}$ & $\begin{array}{c}293 \\
(57,3- \\
6224)\end{array}$ & $\begin{array}{c}64,9 \\
(41,4- \\
83,2)\end{array}$ & $\begin{array}{c}116 \\
(64,4- \\
3286)\end{array}$ \\
\hline p Wilcoxon Test & \multicolumn{2}{|c|}{0.4} & \multicolumn{2}{|c|}{0.07} & \multicolumn{2}{|c|}{0.005} \\
\hline $\mathrm{MN}, \mathrm{pg} / \mathrm{ml}$ & $\begin{array}{c}5.2 \\
(1.06-46.7)\end{array}$ & $\begin{array}{c}17.7 \\
(1.52-39)\end{array}$ & $\begin{array}{c}3.8 \\
(3.6-7)\end{array}$ & $\begin{array}{c}42,1 \\
(3,8- \\
47,4)\end{array}$ & $\begin{array}{c}6,5 \\
(0,53- \\
10,2)\end{array}$ & $\begin{array}{c}6,9 \\
(1,63- \\
45,2)\end{array}$ \\
\hline p Wilcoxon Test & \multicolumn{2}{|c|}{0.9} & \multicolumn{2}{|c|}{0.1} & \multicolumn{2}{|c|}{0.06} \\
\hline $\mathrm{NMN}, \mathrm{pg} / \mathrm{ml}$ & $\begin{array}{c}8.4 \\
(0.61-30.6)\end{array}$ & $\begin{array}{c}40.5 \\
(6.8- \\
53.3)\end{array}$ & $\begin{array}{c}8.8 \\
(0.46- \\
32.1)\end{array}$ & $\begin{array}{c}5,7 \\
(2,9- \\
47,3)\end{array}$ & $\begin{array}{c}4,8 \\
(0,97- \\
38,3)\end{array}$ & $\begin{array}{c}12,9 \\
(2,2- \\
37,5)\end{array}$ \\
\hline p Wilcoxon Test & \multicolumn{2}{|c|}{0.07} & \multicolumn{2}{|c|}{0.6} & \multicolumn{2}{|c|}{0.5} \\
\hline $\mathrm{AD}, \mathrm{pg} / \mathrm{ml}$ & $\begin{array}{c}82 \\
(34.5-116)\end{array}$ & $\begin{array}{c}60.1 \\
(14-121)\end{array}$ & $\begin{array}{c}42 \\
(28.7- \\
134)\end{array}$ & $\begin{array}{c}53,1 \\
(6,7- \\
105)\end{array}$ & $\begin{array}{c}75,3 \\
(30,9- \\
156)\end{array}$ & $\begin{array}{c}51,5 \\
(25,7- \\
95,8)\end{array}$ \\
\hline $\mathrm{p}$ Wilcoxon Test & \multicolumn{2}{|c|}{0.5} & \multicolumn{2}{|c|}{0.7} & \multicolumn{2}{|c|}{0.045} \\
\hline $\mathrm{NA}, \mathrm{pg} / \mathrm{ml}$ & $\begin{array}{c}105 \\
(35.1-179)\end{array}$ & $\begin{array}{c}227 \\
(126- \\
628)\end{array}$ & $\begin{array}{c}79 . \\
(40.1- \\
98.4)\end{array}$ & $\begin{array}{c}540 \\
(312- \\
578)\end{array}$ & $\begin{array}{c}153 \\
(69,3- \\
363)\end{array}$ & $\begin{array}{c}505 \\
(244- \\
818)\end{array}$ \\
\hline $\mathrm{p}$ Wilcoxon Test & \multicolumn{2}{|c|}{0.0009} & \multicolumn{2}{|c|}{0.001} & \multicolumn{2}{|c|}{0.001} \\
\hline $\mathrm{DA}, \mathrm{pg} / \mathrm{ml}$ & $\begin{array}{c}102 \\
(34.1-311)\end{array}$ & $\begin{array}{c}242 \\
(88.1- \\
344)\end{array}$ & $\begin{array}{c}34 \\
(13.7- \\
48.1) \\
\end{array}$ & $\begin{array}{c}47,8 \\
(17,0- \\
79,9)\end{array}$ & $\begin{array}{c}25,2 \\
(14,2- \\
114)\end{array}$ & $\begin{array}{c}91,4 \\
(41,9- \\
202)\end{array}$ \\
\hline p Wilcoxon Test & \multicolumn{2}{|c|}{0.08} & \multicolumn{2}{|c|}{0.3} & \multicolumn{2}{|c|}{0.003} \\
\hline $\mathrm{AD} / \mathrm{MN}$ & $\begin{array}{c}5.1 \\
(2.4-33)\end{array}$ & $\begin{array}{c}3.2 \\
(1.16- \\
13.3)\end{array}$ & $\begin{array}{c}35.1 \\
(13.0- \\
149)\end{array}$ & $\begin{array}{c}0,15 \\
(0,13- \\
27,4)\end{array}$ & $\begin{array}{c}23,2 \\
(8,0- \\
122)\end{array}$ & $\begin{array}{c}3,1 \\
(0,49- \\
58,0)\end{array}$ \\
\hline $\mathrm{p}$ Wilcoxon Test & \multicolumn{2}{|c|}{0.9} & \multicolumn{2}{|c|}{0.1} & \multicolumn{2}{|c|}{0.03} \\
\hline NA/NMN & $\begin{array}{c}5.5 \\
(3.3-25.7)\end{array}$ & $\begin{array}{c}24.4 \\
(5.9- \\
31.1)\end{array}$ & $\begin{array}{c}4.0 \\
(3.05- \\
335)\end{array}$ & $\begin{array}{c}95,3 \\
(12,1- \\
109)\end{array}$ & $\begin{array}{c}22,7 \\
(8,1- \\
201) \\
\end{array}$ & $\begin{array}{c}45,7 \\
(13,1- \\
69,3)\end{array}$ \\
\hline
\end{tabular}




\begin{tabular}{|c|c|c|c|c|c|c|}
\hline p Wilcoxon Test & \multicolumn{2}{|c|}{0.7} & \multicolumn{2}{|c|}{1.0} & \multicolumn{2}{|c|}{0.9} \\
\hline DA/NA & $\begin{array}{c}0.95 \\
(0.29-3.42)\end{array}$ & $\begin{array}{c}0.63 \\
(0.20- \\
2.36)\end{array}$ & $\begin{array}{c}0.43 \\
(0.25- \\
0.70)\end{array}$ & $\begin{array}{c}0,13 \\
(0,03- \\
0,30)\end{array}$ & $\begin{array}{c}0,33 \\
(0,09- \\
0,56)\end{array}$ & $\begin{array}{c}0,21 \\
(0,05- \\
0,57)\end{array}$ \\
\hline $\mathrm{p}$ Wilcoxon Test & \multicolumn{2}{|c|}{0.7} & \multicolumn{2}{|c|}{0.1} & \multicolumn{2}{|c|}{0.7} \\
\hline NA/AD & $\begin{array}{c}1.3 \\
(0.85-3.37)\end{array}$ & $\begin{array}{c}6.8 \\
(1.65- \\
21.17)\end{array}$ & $\begin{array}{c}2.0 \\
(0.49- \\
2.52)\end{array}$ & $\begin{array}{c}8,0 \\
(3,0- \\
27,3)\end{array}$ & $\begin{array}{c}2,4 \\
(1,05- \\
5,99)\end{array}$ & $\begin{array}{c}10,1 \\
(4,31- \\
24,55)\end{array}$ \\
\hline $\mathrm{p}$ Wilcoxon Test & \multicolumn{2}{|c|}{0.007} & \multicolumn{2}{|c|}{0.008} & \multicolumn{2}{|c|}{0.00001} \\
\hline $\mathrm{NA} /(\mathrm{AD}+\mathrm{NMN})$ & $\begin{array}{c}0.85 \\
(0.56-1.07)\end{array}$ & $\begin{array}{l}6.05 \\
(2.5- \\
11.5)\end{array}$ & $\begin{array}{c}0.59 \\
(0.001- \\
1.7)\end{array}$ & $\begin{array}{l}10,67 \\
(2,9- \\
45,6)\end{array}$ & $\begin{array}{c}2,86 \\
(0,82- \\
3,83)\end{array}$ & $\begin{array}{c}5,13 \\
(2,00- \\
20,8)\end{array}$ \\
\hline $\mathrm{p}$ Wilcoxon Test & \multicolumn{2}{|c|}{0.008} & \multicolumn{2}{|c|}{0.1} & \multicolumn{2}{|c|}{0.005} \\
\hline
\end{tabular}

The maximum values recorded in the individuals of this group were about $400 \mathrm{pg} / \mathrm{ml}$, which was 4 times higher than the standard values. The mean group concentration of norepinephrine was in the lower third of the reference interval (up to $600 \mathrm{pg} / \mathrm{ml}$ ) in both examinations, and only $25 \%$ of individuals had an increase in the level of this analyte beyond the upper limit in the dynamics of the examination. At the same time, the average group level of norepinephrine for $4-5$ years increased 1.4 times $(-0.2 ; 6.1)$. The content of adrenaline in this group in $70-75 \%$ of the examined did not exceed the maximum permissible values (up to $100 \mathrm{pg} / \mathrm{ml}$ ) in the first and second studies. An increase in the level of NA in the dynamics of the survey led to an increase in the coefficients reflecting the degree of his metabolism: NA / AD and NA / (AD + NMN). It should be noted that the NMN level also increased, but did not reach the level of statistical significance. Despite the presence of abnormalities in the content of catecholamines in a certain number of people in this group, the level of their metabolites (MN and NMN) did not exceed the reference values either according to the average group values or according to individual data (up to $90 \mathrm{pg} / \mathrm{ml}$ ). The average group values of histamine were also higher than the normative values (up to $1 \mathrm{ng} / \mathrm{ml}$ ), and the level of serotonin was below the refence $(63-200 \mathrm{ng} / \mathrm{ml}$ ) upon repeated examination. Meanwhile, more than $50 \%$ of the subjects of this group had high levels of histamine and low concentration of serotonin on re-examination, while at the initial observation they were about $40 \%$ and less than $25 \%$, respectively.

Patients in the initial period of CMI had increased histamine levels at two points of examination in more than $50 \%$ of cases. The recorded maximum concentration of this analyte was more than 2 times higher than the values of the representatives of the previous group. An increase in the serotonin content in the blood in the dynamics of the examination, both of the average group value and of individual indicators in more than $50 \%$ of cases, was also a distinctive feature. Moreover, in some cases, the maximum values exceeded the established upper limit by more than 30 times. In patients with intoxication in the initial period, the level of dopamine was within the standard values, in contrast to the group of persons without occupational disease. There were isolated cases of exceeding the reference limit of noradrenalin concentration during repeated examination (less than 10\%) and in $25 \%$ of individuals - the level of adrenaline. The content of catecholamine metabolites corresponded to that in the individuals of the previous group. It should be noted that in patients in the initial period of intoxication in the dynamics of the examination, only the NA content changed statistically significantly: 3.2 times $(0.7 ; 8.3)$, which was accompanied by a statistically significant increase in the NA / AD coefficient, $\mathrm{p}<0.008$.

The maximum number of indicators that changed in the dynamics of the survey was recorded in the group of the long-term period of SRI. The DA level underwent the greatest change - it increased by $284 \%(-5 ; 636)$. The concentration of its conversion product NA 
also increased statistically significantly - by $124 \%(-15 ; 683)$, while the AD level decreased on average by $42 \%(-77 ; 76)$. The DA / NA ratio did not change over time, and the NA / $\mathrm{AD}$ ratio increased. In persons of this group, the serotonin content also underwent a change - it increased by $1.6(-0.3 ; 71)$ and histamine - by 0.8 times $(-0.3 ; 2.3)$.

\section{Discussion}

According to the results of clinical examination, autonomic dysfunction was diagnosed in more than $50 \%$ of those working in contact with mercury, in $55.6 \%$ and $83.3 \%$ of patients in the long-term and initial period of chronic respiratory infections, respectively [9] One of the important manifestations of neurointoxication with mercury was encephalopathy of toxic genesis. Patients with this disease more often complained of headaches, non-systemic dizziness, tinnitus or head noises, decreased memory for current events, as well as a large number of complaints related to the psychoemotional sphere [10].

We revealed involvement in the pathological process of the formation of disorders of the nervous system during mercury intoxication of changes in the level of NA. Its effect associated with a predominant effect on $\alpha$-adrenergic receptors, participating in the pathogenesis of arterial hypertension $(\mathrm{AH})$, recorded in most individuals exposed to mercury (Figure 1) [7]. It should also be taken into account that under the conditions of activation of oxidative stress processes catecholamines and other compounds undergo oxidation under the action of ceruloplasmin, contributing to the further activation of oxidative processes.

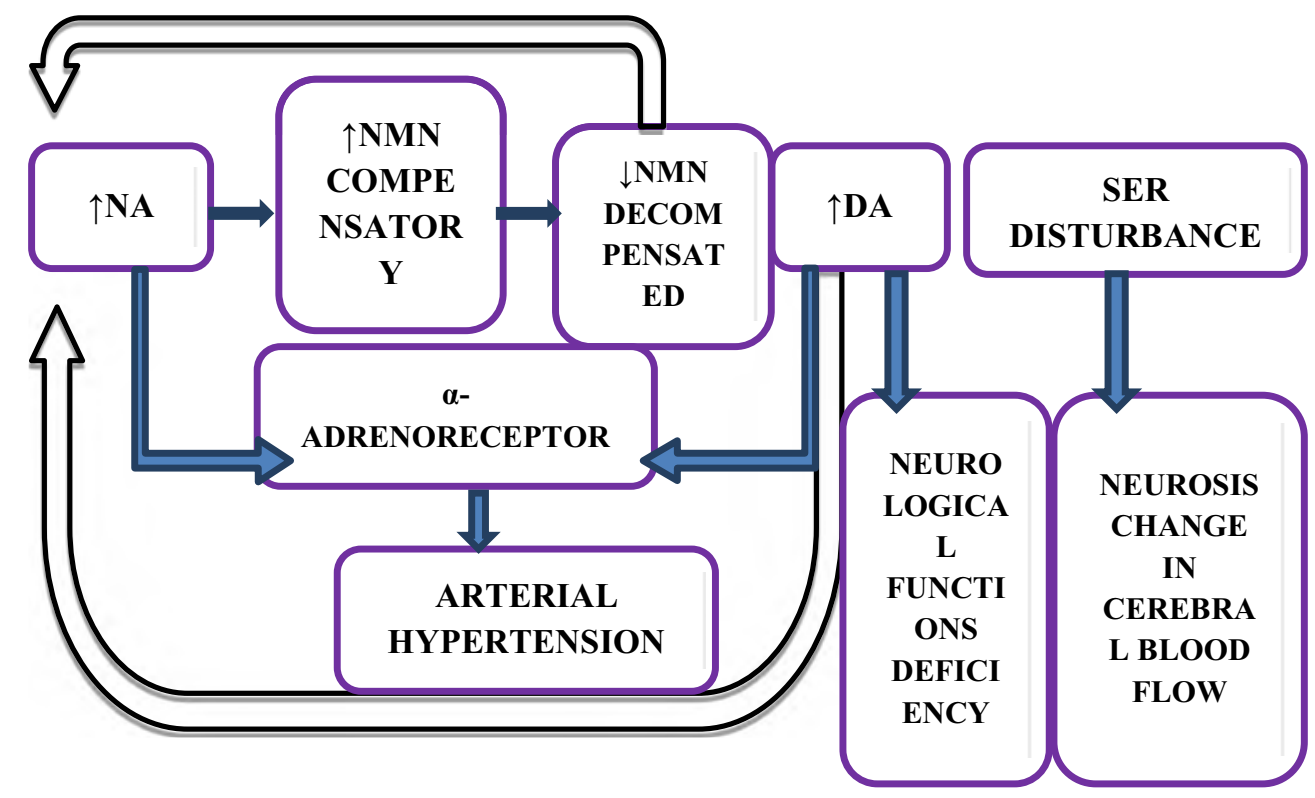

Fig. 1. The role of neurochemical parameters in the chronic mercury intoxication development

Previously, the increase of the ceruloplasmin concentration was found in all workers in contact with mercury and in persons in the initial and distant period of CMI [11]. In this case, the prooxidant role of this analyte in the processes of impaired nerve impulse conduction was established. It was confirmed by the presence of a negative correlation between its concentration and the amplitude of the M-response along the median and ulnar nerves [12]. 
Dopamine plays an important role in providing cognitive performance. So, the activation of dopaminergic transmission is necessary in the process of switching cognitive activity. A sharp increase of extracellular dopamine is a trigger factor in the development of cascading events leading to neurological deficit. The dopaminergic system is under control or controls most of the neurotransmitter systems itself. Wherein, the serotonergic system is in antagonistic relationships with dopaminergic [13]. Dopamine almost does not penetrate the blood-brain barrier with its integrity. At the same time, if it is disturbed, dopamine can affect individual brain structures [13]. In high concentrations, it stimulates $\alpha$ - and $\beta$ adrenergic receptors, causing an increase in systolic blood pressure (Figure 1). The effect of dopamine on adrenergic receptors is also associated with its ability to release NA from granular presynaptic depots [13]. In our studies an increase in blood dopamine levels in patients with mercury intoxication is accompanied by a decompensated increase in the concentration of NA in the mechanisms of which dopamine is obviously involved (Figure 1).

At the same time, a previous analysis of changes in indicators of the cognitive and emotional-personal spheres revealed that patients in the distant period of CMI have a more pronounced decrease in short-term, distant, operational, figurative memory, cognitive potential, and indicators that characterize the attention function and emotionally-personal sphere than in workers with the first diagnosis of CMI [8]. Disruption of dopamine regulation may be the basis of the pathogenesis of these disorders.

It is known that the largest amount of serotonin in the central nervous system is concentrated in the vegetative structures and the reticular formation of the brain, where it has an exciting effect on the parasympathetic section of the trunk and limbic zone [14]. Outside the central nervous system, it is found in platelets. There, serotonin is physiologically consumed like its active uptake by neuron synaptosomes $[14,15]$. In our studies, no statistically significant dynamic changes in serotonin concentration were detected. But the widest possible range of fluctuations in its concentration was observed in patients with CMI, which may also be due to the development of an organic personality disorder of a psychopathic type (Figure 1) [11]. An increase in the content of free plasma serotonin is associated with a decrease in cerebral vascular tone, their excessive stretching and the progression of perivascular edema [16], which may be significant in the development of hydrocephalus, which is observed in $92 \%$ of patients in the distant period of mercury intoxication.

Thus, an increase in NA concentration is characteristic of individuals exposed to mercury. At this stage, the increase of the level of NA was partially offset by its transition to the inactive metabolite NMN.

The increase in NA concentration was not accompanied by the increase of the level of its metabolites in individuals with CMI in the initial period. These changes were joined by the increase of the concentration of dopamine, serotonin and histamine in patients in the distant CMI period.

\section{References}

1. S. S. Patel, S. Tomar, D. Sharma, N. Mahindroo, M. Udayabanu, N. Biobehav, Rev, 74, 76-97 (2017) doi: 10.1016/j.neubiorev.2017.01.008

2. G. Morris, B. S. Fernandes, B. K. Puri, A. J. Walker, A. F. Carvalho, M. Berk, A. N. Z. J. Psychiatry, 52, 924-948 (2018) doi: 10.1177/0004867418796955

3. H. Lohren, J. Bornhorst, H.-J. Galla, T. Schwerdtle, Metallomic, 7, 1420-1430 (2015) doi: $10.1039 / \mathrm{c} 5 \mathrm{mt} 00171 \mathrm{~d}$ 
4. H. Lohren, J. Bornhorst, R. Fitkau, G. Pohl, H.-J. Galla, T. Schwerdtle, BMC Pharmacol Toxicol, 17, 63 (2016) doi: 10.1186/s40360-016-0106-5

5. N. Vanduyn, R. Settivari, G. Wong, R. Nass, Toxicol Sci. 118, 613-624 (2010) doi: 10.1093/toxsci/kfq285

6. R. Pamphlett, S. Kum Jew, Biometals, 31, 807-819 (2018) doi: 10.1007/s10534-0180124-4

7. I. Kudaeva, O. Dyakovich, E. Katamanova, O. Popkova, L. Masnavieva, Hygiene and sanitation, 94, 68-72 (2015) doi: 10.18821/0016-9900-2018-97-10-990-994

8. E. Katamanova, O. Shevchenko, V. Rukavishnikov, S. Shayakhmetov, O. Lakhman, Proceedings of the Conference on Information Technologies in Science, Management, Social Sphere and Medicine (ITSMSSM 2016), 192-196 (2016)

9. O. Lakhman, V. Rukavishnikov, S. Shayakhmetov, L. Sosedova, E. Katamanova, G. Bodienkova, O. Shevchenko, D. Rusanova, O. Zhurba, Occupational medicine and industrial ecology, 9, 82-83 (2015)

10. V. Rukavishnikov, O. Lakhman, L. Sosedova, S. Shayakhmetov, G. Bodienkova, E. Katamanova, Occupational medicine and industrial ecology, 4, 1-6 (2014)

11. L. Masnavieva, L. Budarina, I. Kudaeva, Acta Biomedica Scientifica, 74, 115-118 (2010)

12. D. Russanova, I. Kudaeva, O. Lakhman, Siberian Medical Journal (Irkutsk), 105, 214$216(2011)$

13. J. D Berke, Nat Neurosci, 21(6), 787-793 (2018) doi: 10.1038/s41593-018-0152-y.

14. I. Timotijević, Ž. Stanković, M. Todorović, S. Z. Marković, D. A. Kastratović, Psychiatr. Danub., 3, 326-330 (2012)

15. M. D. Gershon, Trans Am Clin Climatol Assoc, 123, 268-280 (2012)

16. T. Yokoyama, N. Nakamuta1, T. Kusakabe, Y. Yamamoto, Brain Res, 30, 1596:12635 (2015) doi: 10.1016/j.brainres.2014.11.037. 